\title{
ULTRASTRUCTURE OF GRANULAR CELL CHANGE IN A WILM'S TUMOR
}

\author{
V. EDWARDS, C. SENGER, J. HWANG, H. ROSENBERG, and C. SMITH \\ Division of Pathology, Department of Pediatric Laboratory Medicine, The Hospital for Sick \\ Children, Toronto, Ontario, Canada.
}

The presence of heterologous elements in Wilm's tumors is well established. ${ }^{1}$ However, granular cell changes in these tumors remains controversial and is poorly understood. ${ }^{2,3}$ In our case, a lesion is seen that contains typical areas of blastema (as seen in Wilm's tumor) admixed with large, oncocytic cells with eosinophilic cytoplasm, arising from the blastemal component. These cells show by immunohistochemistry and ultrastructurally the features as seen in granular cell tumor.

A 7-month-old infant presented with a urinary tract infection at 6 months of age. CT scan showed a $2.5 \mathrm{~cm}$ mass in the lower pole of the right kidney. A right nephrectomy was performed, including sampling of regional lymph nodes that were all negative for metastatic tumor. Wilm's tumor, stage I was diagnosed and the child was treated with the Wilm's tumor protocol with additional chemotherapy for 4 months with vincristine and dactinomycin. Currently, 24 months after presentation, the infant remains free of recurrent tumor.

Sections of the right kidney and 5 regional lymph nodes were fixed with buffered formalin and embedded in paraffin for light microscopy and in Universal Fixative with postfixation in $1 \%$ Osmium Tetroxide and embedding in Epon, for transmission electron microscopy. Immunohistochemistry was performed with antibodies for S100, NSE, cytokeratin, vimentin desmin, chromogranin, lysozyme, CD57 (Leu7), Wt1, and MIB-1.

Light microscopy of this kidney tumor shows a lesion with a serpentine blastemal pattern infiltrating the surrounding kidney. Admixed with the blastema are large cells with coarse, granular, eosinophilic cytoplasm. These cells are strongly PAS and PAS-diastase positive. By immunohistochemistry, these granular cells show weak cytoplasmic staining for vimentin and strong nuclear staining for $\mathrm{Wt}-1$. This staining pattern was also seen in the surrounding blastemal component. The MIB-1 staining was higher by $30 \%$ in the granular cell component compared to the blastema. All of the other markers, including the histiocyte makers, were negative. Ultrastructural evaluation showed the blastemal component merged with clusters of large polygonal cells which contained copious, pleomorphic, osmiophilic lysosomes. These large cells have long cytoplasmic extensions and contained round to oval nuclei, punctate small nucleoli, and a paucity of organelles including mitochondia and short strands of rough endoplasmic reticulum (Fig.A). Noteworthy in these cells are the abundant, single, membrane -bound, variably sized lysosomes, with a heterogenous, granular, pale, lamellar, membranous substructure (Fig. B). Poorly formed junctions, duplicated basal lamina and broadbanded collagen at the edge of the clusters are also seen. 
Wilm's tumor is the most frequent stromal tumor in childhood. Inthese tumors, heterologous elements such as smooth muscle, striated muscle, adipose tissue, cartilage, bone and neural elements have been reported. ${ }^{1,4,5}$ The granular cells in our case show the sub-structural characteristics of Schwann cells (basal lamina which is sometimes duplicated, broad-banded collagen, long cytoplasmic extensions, cytoplasmic lysosomes) but do not show the immunohistochemical staining pattern for Schwann cells (positive CD 57, and S100) as is seen in the majority of adult granular cell tumors. ${ }^{6}$ Our case shows the typical findings seen ultrastructurally and immunohistochemically for granular cell tumors but does not support a Schwann cell origin. These granular cells could be part of the uncommitted blastemal component or represents a secondary degenerative change associated with this tumor.

\section{REFERENCES}

1. Magee JF et al., Histopathology, 20(1992) 427.

2. Ordonez NG. Adv Anat Pathol, 6 (1999) 186.

3. Gonzalez-Crussi F. Boca Raton, Florida, CRC Press, 1984; pp 180-206.

4. Klapproth H. J Urol 81 (1959) 633

5. Hussong JW et al., Pediatr Dev Pathol 3 (2000) 561.

6. Franburg-Schmith JC et al., Am J Surg Pathol 22 (1998)779.

7. Melaragno MJ et al., Hum Pathol 24(1993) (7) 805
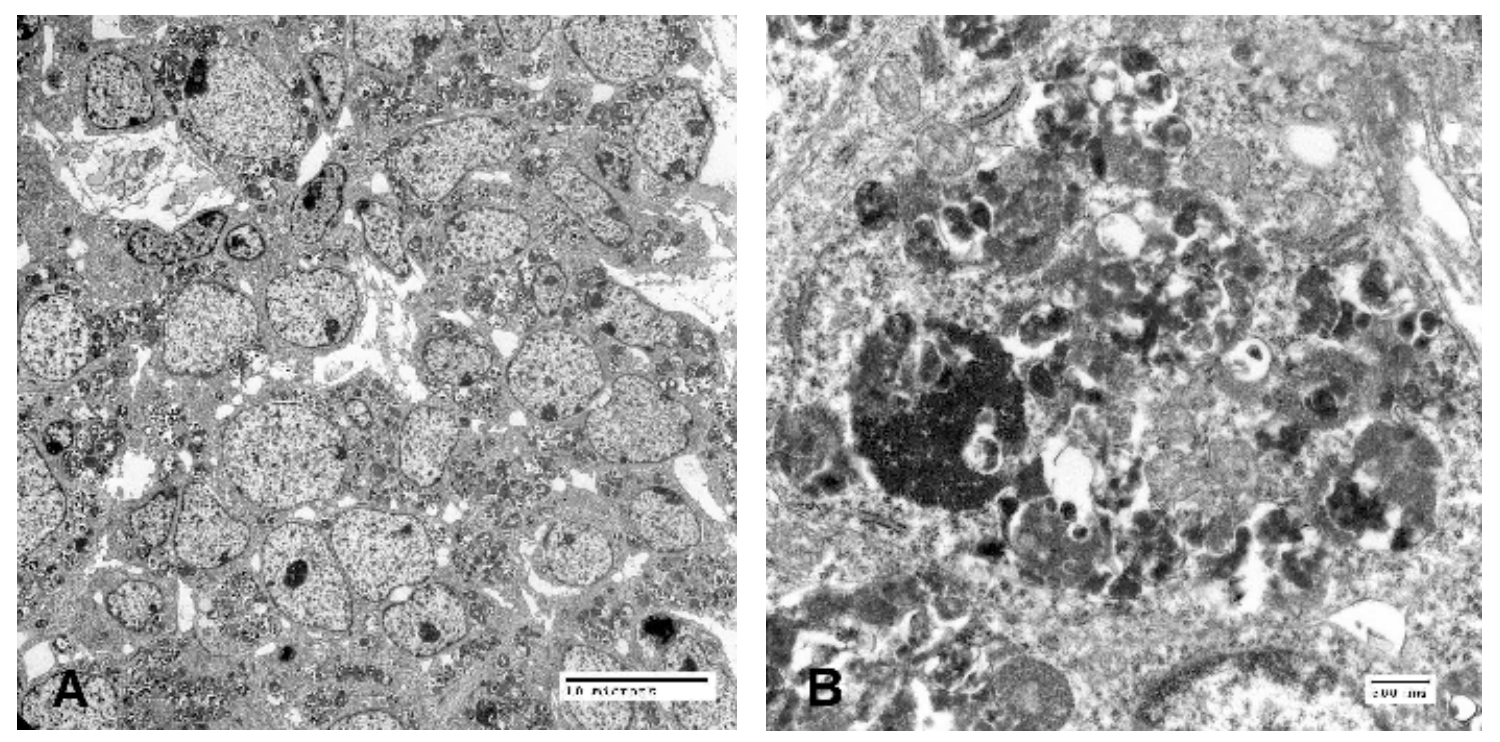

Figure A. Low power electron micrograph to show the closely apposed granular cells. Note the abundant pleomorphic lysomes which fill up the cytoplasm of these cells. Figure B. High power view to show the heterogeneous contents of the lysomes. 